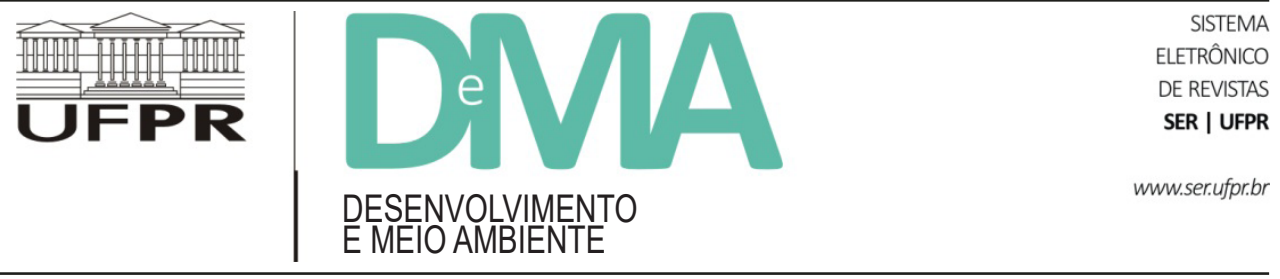

\title{
¿Puede el Estado hacer de la agroecología un fenómeno masivo? Experiencias de políticas públicas en América Latina1
}

\author{
Pode o Estado fazer da agroecologia um fenómeno de massa? \\ Experiências de políticas públicas na América Latina
}

\section{Can the state take agroecology to scale? Public policy experiences in Latin American}

\author{
Omar Felipe GIRALDO ${ }^{1,2^{*}}$, Nils McCUNE ${ }^{3}$ \\ ${ }^{1}$ Universidad Nacional Autónoma de México (UNAM), Escuela Nacional de Estudios Superiores (ENES), Mérida, Yucatán, México. \\ ${ }^{2}$ El Colegio de la Frontera Sur (ECOSUR), San Cristóbal de Las Casas, Chiapas, México. \\ ${ }^{3}$ Universidad de Vermont (UVM), Burlington, VT, EUA. \\ *E-mail de contacto: omarfgiraldo@gmail.com
}

Artículo recibido en 7 de junio de 2021, publicado en 30 de noviembre de 2021.

\begin{abstract}
RESUMEN: En este artículo discutimos la experiencia de las políticas a favor de la agroecología implementadas en Cuba y en los países latinoamericanos que dieron un giro a la izquierda en los primeros años del siglo XXI y que en la actualidad enfrentan un resurgimiento de las fuerzas políticas de derecha. Aunque los casos de estudio enseñan que es posible abrir espacios y momentos de ruptura en los regímenes de poder, existe un riesgo cuando los esfuerzos de los movimientos sociales terminan absorbidos en colaboraciones con el Estado. En realidad la agroecología se mueve al filo de la navaja en donde hay riesgos de ambos lados. Por una parte, al participar en la institucionalización de la agroecología, los movimientos pueden quedar incorporados a las reglas establecidas, teniendo que moverse en un sistema cuyo fin es preservar los intereses de la clase dominante. Y por otra, no hacerlo podría impedir que se modifique, aunque sea parcialmente, la razón de Estado en torno a la
\end{abstract}

\footnotetext{
${ }^{1}$ Este artículo fue publicado originalmente en inglés en: Giraldo, O. F.; McCune, N. Can the state take agroecology to scale? Public policy experiences in agroecological territorialization from Latin America. Agroecology and Sustainable Food Systems, 43(7-8), 785-809, 2019.
} 
política agroalimentaria, apoyando de forma indirecta a la creación de más obstáculos para que la agroecología pueda territorializarse. En el fondo de la cuestión está en juego el carácter político de la agroecología: seguir apostando por la reforma o por la revolución.

Palabras clave: territorialización de la agroecología; agroecología política; Estado; movimientos sociales; revolución.

RESUMO: Neste artigo discutimos a experiência das políticas pró-agroecologia implementadas em Cuba e em países latino-americanos que se deslocaram para a esquerda nos primeiros anos do século XXI e que atualmente enfrentam o surgimento de forças políticas de direita. Embora os casos estudados mostrem que é possível abrir espaços e momentos de ruptura dentro dos regimes de poder, acreditamos que há um risco quando os esforços dos movimentos sociais acabam sendo absorvidos em colaborações com o Estado. Na realidade, a agroecologia se move no fio da navalha onde há riscos em ambos os lados. Por um lado, ao participar da institucionalização da agroecologia, os movimentos podem ser incorporados às regras estabelecidas do jogo, tendo que se mover dentro de um sistema cujo objetivo é preservar os interesses da classe dominante. Mas, por outro lado, não fazê-lo poderia impedir que a raison d'état em torno da política agroalimentar fosse modificada, mesmo que parcialmente, apoiando indiretamente a criação de ainda mais obstáculos para que a agroecologia seja territorializada. No cerne da questão está a natureza política da agroecologia: continuar a optar pela reforma ou pela revolução.

Palavras-chave: territorialização da agroecologia; agroecologia política; estado; movimentos sociais; revolução.

ABSTRACT: In this article we discuss the experience of agroecology policies implemented in Cuba and in Latin American countries that made a shift to the left in the early years of the 21 st century and are currently facing an emergence of right-wing political forces. Although the cases studied show that it is possible to open spaces and moments of rupture within the regimes of power, we believe that there is a risk when the efforts of social movements end up absorbed in collaborations with the State. Agroecology moves on the razor's edge where there are risks on both sides. On the one hand, by participating in the institutionalization of agroecology, movements may be incorporated into the established rules of the game, having to move within a system whose purpose is the preservation of the interests of the dominant class. But on the other hand, not doing so could prevent the modification, even partially, of the raison d'état around agri-food policy, indirectly supporting the creation of even more obstacles to the territorialization of agroecology. At the heart of the matter is the political nature of agroecology: to continue to opt for reform or revolution.

Keywords: territorialization of agroecology; political agroecology; state; social movements; revolution.

\section{Introducción}

El rápido ascenso de la derecha en la política brasileña es emblemático de un fenómeno regional: ninguna de las reformas institucionales de los gobiernos de centroizquierda latinoamericanos desde 1999 están a salvo de los ataques revisionistas, neoconservadores y neofascistas. Esta situación histórica particularmente preocupante se está desarrollando a pesar de que algunos de los esfuerzos internacionales más importantes para institucionalizar la agroecología y los derechos de los campesinos están dando sus frutos. En abril de 2018 se celebró el segundo simposio internacional de la FAO con el nombre "Ampliación de la agroecología para alcanzar los objetivos de desarrollo sostenible", 
y en el mismo año se aprobó como ley internacional la Declaración de las Naciones Unidas sobre los derechos de los campesinos y otras personas que trabajan en zonas rurales (Gliessman, 2018; LVC, 2018). Estas tendencias contradictorias nos invitan a discutir qué estrategias deben utilizarse para ampliar y acelerar las transiciones hacia sistemas alimentarios agroecológicos.

Este texto contribuye a la documentación y análisis de cómo las políticas públicas pueden ayudar a territorializar la agroecología, a la vez que estudia las posibilidades reales de lo que puede realizarse desde sus instituciones en nuestros días. Nuestra historia comienza en los años noventa cuando en medio del auge del neoliberalismo triunfalista estalla una serie de desafíos al capitalismo transnacional y a la hegemonía de Estados Unidos en toda América Latina. Se trató de un puñado de proyectos políticos progresistas que, a menudo, encontraron su principal fuente de fortaleza en los movimientos campesinos e indígenas que rechazaron los proyectos de privatización, mientras elaboraban visiones para un Estado revitalizado y democratizado. En efecto, los movimientos populares fueron determinantes para crear campañas electorales exitosas, y para que, una vez posesionados, los gobiernos declararan la descolonización de las instituciones, el control nacional sobre los recursos clave y la soberanía alimentaria como prioridades del Estado (McKay et al., 2014). Fue en ese contexto en el que varios gobiernos de la región intentaron, en diferentes grados, institucionalizar la agroecología (McCune, 2017; Sabourin et al., 2017).

A pesar de este importante avance y conquista de los movimientos sociales, desde 2009 el fenómeno de los "regímenes progresistas" en América Latina empezó a mostrar una vulnerabilidad creciente como resultado de tres factores principales: 1) la imposibilidad de transitar de modelos económicos extractivos a modelos económicos regenerativos; 2) la incapacidad de las fuerzas de izquierda para movilizar a la sociedad de forma permanente hacia una democratización de abajo arriba, que incluya estructuras culturales, económicas y sociales, y 3) la aplicación exitosa de las estrategias de Estados Unidos conocidas como guerras híbridas de cuarta generación, golpes blandos o revoluciones de color, cuyo objetivo es controlar o deshacerse de gobiernos no deseados, al tiempo que restaura regímenes neoliberales convencionales, o logra victorias políticas de extrema derecha que suelen reprimir de manera intensa a los migrantes, a las minorías religiosas y sexuales, así como a los defensores de la tierra y el territorio.

Estos factores en conjunto delinean el fin del primer ciclo progresista y llaman a que el movimiento social agroecológico debata la viabilidad de emprender reformas institucionales duraderas en sus intentos de territorializar la agroecología. A ese contexto hostil debe sumarse que los movimientos populares casi siempre negocian con el Estado desde una posición de debilidad, en la medida en que representan a comunidades organizadas que participan en complejas estrategias de reproducción y resistencia cotidiana, en lugar de encarnar un proyecto de clase unificada cuyo fin sea la conquista de la hegemonía (Veltmeyer, 2019). Estas negociaciones asimétricas a menudo se justifican en aras de conformar marcos basados en los derechos dentro de los regímenes políticos existentes, para obtener algunos logros que respondan a los fines de sus disputas territoriales y de recursos. El contexto actual, sin embargo, en el que los cambios de régimen contra los gobiernos 
progresistas se han convertido en el orden del día (Bello, 2018), plantea una interrogante nueva a los movimientos agroecológicos: ¿qué se espera ganar a través de la negociación con gobiernos que probablemente serán reemplazados por regímenes neoliberales o neofascistas?

Aquí abordamos la cuestión del Estado, desde la perspectiva de la búsqueda de métodos políticos y sociales para hacer de la agroecología un fenómeno masivo (Parmentier, 2014; Mier y Terán et al., 2018; Nicholls \& Altieri, 2018). Situaremos nuestra discusión en el creciente reconocimiento institucional de la agroecología como una herramienta clave para resolver los problemas que enfrenta el planeta, así como en la evolución del pensamiento de los movimientos populares respecto del poder del Estado. Nuestro propósito es analizar cómo, por qué y bajo qué circunstancias los movimientos agroecológicos deben comprometerse con el Estado en el diseño o la implementación de políticas públicas. Al mismo tiempo, intentamos atender una pregunta urgente y global: ¿cómo defender los derechos sociales -y enfriar a la Madre Tierra (LVC, 2009)- en el escenario de una creciente política de odio?

El artículo se divide en tres secciones que comenzamos con la descripción del primer ciclo de los regímenes progresistas en Latinoamérica: un proceso de grandes dimensiones y posibilidades, lleno de defensores eufóricos y críticos decepcionados, de esfuerzos mayores de desestabilización por parte de Estados Unidos y una cantidad extraordinaria de elecciones. Los persistentes debates sobre la autenticidad de estos procesos y su lugar en un proyecto emancipatorio global se han dejado de lado por el aplastante avance de la política de derechas en el continente (Scoones et al., 2018), en relación directa con la evolución de las estrategias políticas y militares internacionales aprovechadas por las corporaciones transnacionales y las élites tradicionales.

En la segunda sección definimos tres dominios entrelazados que utilizamos para analizar las políticas públicas desde el punto de vista de la agroecología: el saber, el territorio y la soberanía. En lugar de limitarnos a examinar políticas individuales o partidas presupuestarias destinadas a fomentar la agricultura agroecológica, nos centramos en estos tres principios a escala del sistema de los regímenes sociopolíticos, los cuales pueden apoyar la ampliación de los sistemas alimentarios agroecológicos (Vandermeer et al., 2018). Utilizamos estos principios superpuestos para examinar los aspectos políticos de la territorialización agroecológica en América Latina. Examinamos cómo el saber, el territorio y la soberanía han sido utilizados por el Estado y por los actores no estatales para hacer posible la ampliación de la producción agroecológica de alimentos. Encontramos que la necesidad fundamental del cambio político para la transformación agroecológica es aquella política que interrumpa el poder de los terratenientes y evite o destruya la consolidación de los imperios de los agronegocios. Sostenemos que la agroecología puede florecer en ausencia de estas estructuras de poder regresivas y depredadoras.

En la tercera sección, discutimos nuestra lectura del Estado y de los movimientos populares en este momento histórico del capitalismo global liderado por el capitalismo financiero especulativo, en el que se libra una lucha enconada por obtener el control de los recursos globales. Argumentamos que el Estado no es más sino su propia contradicción, y en tal sentido su control popular y democrático 
es la condición sine qua non para que el pueblo organizado utilice medios legales para detener el ecocidio capitalista; pero al mismo tiempo, las negociaciones de los movimientos con el Estado tienden a generar riesgos asociados a la desmovilización popular, creación de dependencia, efectos nocivos relacionados con las lógicas de los programas públicos, e inestabilidad en la continuidad de la institucionalización ante cambios de régimen político. Concluimos que nada puede reemplazar a los movimientos agroecológicos comprometidos, territoriales y de base como medio de la autodeterminación autónoma y la construcción de la revolución agroecológica.

\section{La construcción y destrucción de los gobiernos “amigos” en América Latina}

Para responder a la pregunta de cuál es el contexto político e institucional que más favorece el escalamiento agroecológico, es ilustrativo observar las transformaciones agrícolas y alimentarias que se están produciendo en Cuba desde 1991 (Machín Sosa et al., 2010). Con el colapso de la Unión de Repúblicas Socialistas Soviéticas (URSS), Cuba perdió a su principal socio comercial justo cuando el gobierno de Estados Unidos intensificó el bloqueo comercial y financiero de la isla. Hay que recordar que este acontecimiento coincidió con la invasión a Irak y la declaración del presidente estadounidense George H. W. Bush de un "nuevo orden mundial" basado en la democracia liberal occidental como la forma final de organización política de toda la humanidad. En realidad, aquel nuevo orden mundial o "dominio del espectro completo", en palabras de Chomsky (2002), significó para los países de América Latina la institucionalización total e irreversible de la terapia de corte neoliberal experimental (Klein, 2007) y de los programas de ajuste estructural, los cuales se terminaban de instalar a medida que los pagos de la deuda externa, las privatizaciones y los choques de mercado expandían enormemente los niveles de pobreza extrema. Como ha sido ampliamente documentado, el gobierno cubano reaccionó de manera totalmente diferente a las nuevas circunstancias y la agricultura agroecológica se convirtió en una forma de resistencia y en una política nacional durante la década de 1990. La política de autosuficiencia alimentaria, basada en el conocimiento de los campesinos locales, combinada con programas tecnológicos reorientados para producir insumos biológicos, huertos urbanos descentralizados y el movimiento agroecológico de Campesino a Campesino, se convirtió en la estrategia para resistir a los embates del nuevo contexto mundial (Fernández et al., 2018).

La ortodoxia de libre mercado del Consenso de Washington, rechazada tempranamente por el Caracazo en 1989, la supervivencia de Cuba y el levantamiento zapatista de 1994, se vio trastocada permanentemente por los triunfos electorales del venezolano Hugo Chávez en 1998, 1999, 2004, 2006, 2009 y 2012 (Wilpert, 2007). Chávez argumentó que América Latina y el Caribe solo habían logrado una independencia parcial y formal, y que se necesitaba una "segunda independencia" basada en parte en la redistribución de la riqueza, para descolonizar económica y culturalmente el continente (Escobar, 2010). Chávez y el presidente cubano Fidel Castro formaron laAlianza Bolivariana Alternativa para los Pueblos de Nuestra América (ALBA) en 2004, en respuesta a la propuesta de 
George W. Bush de un Tratado de Libre Comercio de las Américas, conocido como ALCA. En lugar de ALCA, que hubiera abierto todas las economías de la región a la "libre" competencia, el ALBA propuso una integración regional basada en los principios de solidaridad y relaciones complementarias.

A medida que los candidatos progresistas y semiprogresistas fueron elegidos en Argentina (2003), Brasil (2003), Bolivia (2005), Honduras (2005), Nicaragua (2006), Ecuador (2006), Paraguay (2008), Uruguay (2009), El Salvador (2009) y otros países, la alianza del ALBA aumentó y por fin se quebró el aislamiento de Cuba que había durado décadas (Riggirozzi \& Tussi, 2012). La oposición ciudadana al neoliberalismo abrió una amplia conversación sobre el socialismo, el posliberalismo, el poscapitalismo, la autonomía y la descolonización. Surgió una resistencia de varias capas al capitalismo neoliberal en América Latina: los gobiernos de Brasil, Argentina y Uruguay se convirtieron en ejemplos de una izquierda "responsable" que buscaba reducir la pobreza a través de un enfoque neodesarrollista que ampliaba las inversiones tanto capitalistas como sociales; las revoluciones populares en Ecuador y Bolivia utilizaron nuevas Constituciones para defender el concepto indígena del Buen Vivir como antípoda del desarrollo capitalista; y la Venezuela chavista se dedicó a la construcción del Socialismo del Siglo XXI, haciendo un llamado a los movimientos populares urbanos y rurales, a las comunidades afrodescendientes y a los pueblos indígenas a organizar un nuevo tipo de Estado (Katz, 2008). Además del ALBA, las instituciones progresistas de integración regional creadas durante la era de Chávez incluyeron a la Unión de Naciones Suramericanas (UNASUR), Petrocaribe y la Comunidad de Estados Latinoamericanos y Caribeños (CELAC). Este fue un periodo en el que los principios agroecológicos fueron consagrados en la legislación de muchos países latinoamericanos, en particular en las de Venezuela, Bolivia, Ecuador, Brasil, Argentina y Nicaragua.

A los gobiernos progresistas de América Latina se les atribuye en general la drástica reducción de la pobreza extrema, el restablecimiento de la alfabetización, la educación y la atención de la salud como derechos y no como privilegios, y la ampliación de la concepción de ciudadano y Estado para garantizar los derechos históricamente negados de las mujeres, los pueblos indígenas, los afrodescendientes, los campesinos y los trabajadores (Escobar, 2010). Estos gobiernos ampliaron enormemente los servicios sociales y la inversión pública en infraestructura, al tiempo que redujeron o eliminaron la dependencia de los préstamos predatorios del Banco Mundial y el Fondo Monetario Internacional. Sin embargo, ninguno de estos proyectos progresistas encontró la manera de romper definitivamente con las estructuras económicas extractivas que han dominado desde la época colonial, provocando profundos debates dentro de las comunidades de izquierda y los movimientos populares (Stédile, 2017; Andermann, 2018; Veltmeyer, 2019). A pesar de la transformación del paisaje institucional, el papel de la agroecología no ha sido consistente en el giro a la izquierda de América Latina. El papel del sector privado en el procesamiento, distribución y venta de alimentos no ha sido desafiado de forma agresiva por los gobiernos del ALBA, excepto Cuba, que representa un nivel cualitativamente distinto de compromiso con los sistemas alimentarios agroecológicos (Rosset \& Benjamin, 1994; Machín 
Sosa et al., 2010). Otros países de la "marea rosa" de América Latina desde 1999 han seguido, en general, una política de dos vías: apoyando a la agricultura sustentable de los pequeños agricultores, al menos en el plano discursivo, al mismo tiempo que son cómplices de las incursiones transnacionales de los agronegocios y los intereses mineros en los territorios campesinos.

A lo largo de los primeros años de la década de 2000, las élites tradicionales se vieron desplazadas del poder político y enfrentadas a decisiones incómodas: exiliarse en Estados Unidos, organizar una oposición activa a los gobiernos progresistas, retirarse a actividades estrictamente del sector privado, o simplemente esperar una oportunidad. El intento golpista contra Hugo Chávez en 2002 y el paro gerencial petrolero en el mismo año, el levantamiento armado que arrancó al presidente haitiano Jean-Bertrand Aristide del poder en 2004, la rebelión "Media Luna" de las élites terratenientes de ascendencia croata contra el gobierno de Evo Morales en Bolivia durante 2008, el golpe militar contra el presidente hondureño Manuel Zelaya en 2009 y el atentado contra el presidente ecuatoriano Rafael Correa en 2010 son hitos en la evolución de la oposición a los gobiernos progresistas en América Latina y el Caribe (Borón, 2014). El éxito inicial de los gobiernos de izquierda en repulsar estas conspiraciones y revueltas lideradas por las élites, se hallaba en su apoyo comprometido por parte de sectores organizados de la sociedad, en particular las organizaciones del barrio urbano y los movimientos campesinos (Wilpert, 2007). Tomando el ejemplo de Chávez, la reacción común de estos gobiernos ante los intentos golpistas era profundizar los procesos de transformación nacional y mantener la movilización permanente de sectores sociales solidarios. Esta profundización se tradujo en medidas como la nacionalización de los hidrocarburos en Bolivia y Ecuador, así como el compromiso de Hugo Chávez de reemplazar el "Estado burgués" por una democracia comunal y ascendente del poder popular, incluyendo un compromiso explícito con la producción agroecológica (Ciccariello-Maher, 2014).

Sin embargo, todos estos gobiernos se vieron estancados por su incapacidad para erradicar la corrupción en las burocracias del Estado, y muchos observadores denunciaron la existencia de una brecha entre las aspiraciones de las democracias experimentales y las prácticas culturales y sociales arraigadas que reproducen la desigualdad (Katz, 2008). La flagrante contradicción entre las Constituciones políticas y las leyes que reconocían formalmente los derechos de la naturaleza, y las políticas que fomentaban el extractivismo, empujaron a los gobiernos de izquierda hacia el pantano. Muchos académicos y organizaciones no gubernamentales (ONG) progresistas criticaron el "neodesarrollismo redistributivo" de los gobiernos de Venezuela, Bolivia, Ecuador y Nicaragua, por fomentar las industrias extractivas, y por ser demasiado amigables con los intereses capitalistas (Gudynas, 2011). Sin embargo, la mayoría de las organizaciones y movimientos sociales que conforman la Coordinadora Latinoamericana de Organizaciones del Campo (CLOC), expresión continental de La Vía Campesina en América Latina y el Caribe, han estado ligeramente más cualificadas en sus críticas a los gobiernos de izquierda y, en general, han cerrado filas con los movimientos urbanos y los candidatos progresistas durante los ciclos electorales (CLOC, 2015). 
Poco después de que Hugo Chávez muriera de cáncer en 2013, la economía venezolana entró en crisis cuando los precios del petróleo cayeron de 110 USD por barril en junio de 2014 a 22 USD por barril en enero de 2016. A medida que el apoyo financiero venezolano a la economía regional desaparecía, los gobiernos de izquierda se enfrentaban a la perspectiva de recortar programas sociales o de asumir déficits económicos. En este contexto, los movimientos de protesta de la recién creada clase media florecieron en América Latina, generalmente por cuestiones de corrupción. Ya llegado ese momento, las condiciones habían madurado para las operaciones de cambio de régimen más descaradas (Mora, 2018), y el éxito de las "revoluciones de color" dirigidas por Estados Unidos en Europa Oriental y la Primavera Árabe se convirtió en el patrón para aplicaciones similares en América Latina. Las rebeliones de élite que han surgido recientemente reciben apoyo logístico y financiero de la National Endowment for Democracy (NED), que en sus propias publicaciones se ha jactado de construir la capacidad de los grupos de oposición para tomar el control repentino de los medios de comunicación y mantener una narrativa dominante (Waddell, 2018).

La novedosa colaboración de los medios de comunicación oligárquicos tradicionales y las campañas en los medios sociales transforman virtualmente el panorama político de la noche a la mañana, utilizando mensajes previamente desarrollados a través de una extensa investigación política, social, antropológica y psicológica del tipo que ha ganado notoriedad desde el escándalo de Cambridge Analytics. Las plataformas transnacionales de medios sociales Facebook, WhatsApp y Twitter, con dueños en Estados Unidos, desempeñan un papel fundamental para avivar los levantamientos "espontáneos" y sin líderes contra los gobiernos progresistas de la región, con la ayuda de herramientas políticas contemporáneas "post verdad" como noticias falsas, bots y trols para construir un estado de opinión pública que fuerce la salida de los gobiernos progresistas. Las guarimbas extremadamente violentas en Venezuela en 2014 y 2017, el bombardeo mediático previo al juicio de Dilma Rouseff en 2016, el encarcelamiento de Lula y las elecciones de 2018, el arrinconamiento de Nicaragua desde abril de 2018, y el golpe de Estado en Bolivia de 2019, fueron esencialmente operaciones mediáticas, guiadas por las teorías de Gene Sharp (1994) sobre el conflicto asimétrico, en las que los actores no estatales derriban regímenes políticos (Korybko, 2015).

El desmantelamiento de los gobiernos progresistas señala un escalofriante retorno hacia los regímenes autoritarios y neoliberales en América Latina. Las castas tradicionales de élite de terratenientes que llegan en algunos casos, y los extremistas populistas neoliberales en otros, utilizan el poder del Estado para intensificar diversas formas de violencia contra las comunidades indígenas y campesinas, los migrantes internos y globales, las minorías sexuales, los pueblos afrodescendientes, las mujeres y, en general, contra los pobres (Andermann, 2018; Bähre \& Gomes, 2018). El fin del primer ciclo progresista en el continente parece ser el comienzo de un periodo de represión, criminalización y odio intensificados. No solo se han revocado las políticas favorables a la agroecología en estos países, sino que incluso hay casos donde estas se han convertido en herramientas para la represión y la recopilación de información contra los movimientos. 


\section{Por qué, cómo y cuándo de la política pública agroecológica}

¿Qué hay que aprender de esta dura experiencia? ¿Los movimientos sociales desperdician energía preciosa diseñando y exigiendo políticas agroecológicas? Antes de responder a estas preguntas, examinaremos algunas de las políticas agroecológicas creadas en América Latina a través de la dinámica entre los movimientos sociales y los gobiernos progresistas en las últimas dos décadas.

Para empezar, hay que decir que las luchas para llevar la agroecología a escala son realmente recientes, con el movimiento campesino de Nicaragua de finales de los años ochenta y la transición de Cuba en los noventa como los hitos más importantes (Wright, 2005; Holt-Giménez, 2006). Aunque la agroecología haya sido defendida -con ese y otros nombres- por movimientos sociales durante los últimos cuarenta años, fue hasta hace muy poco que el creciente movimiento agroecologista logró incluir el tema en los debates públicos (Wezel et al., 2009). Vale decir que por mucho tiempo la agroecología fue excluida de las discusiones políticas en las instituciones, y que la plataforma política que dio lugar a su paulatina institucionalización fue construida con las luchas de movimientos campesinos a lo largo del siglo XX (Rosset, 2006). Aunque históricamente las luchas fueron principalmente defensivas -en contra del acaparamiento de tierras, la inundación de alimentos exportados en los mercados nacionales, la privatización del agua, la concesión minera, las patentes de semilla-, es en el contexto de los gobiernos progresistas o socialistas, donde se logró conquistar políticas favorables a la agroecología gracias a la presión de una amplia red de actores como el campesinado organizado, pueblos indígenas, sindicatos de trabajadores rurales, ONG, académicos, así como sectores de los gobiernos y la cooperación internacional (Altieri \& Toledo, 2011).

Este breve repaso de las políticas agroecológicas propone tres principios rectores para cambiar las relaciones de poder a favor de la agroecología: saber, territorio y soberanía.

Saber significa la recuperación de los saberes y las tecnologías autóctonas, el intercambio y el diálogo entre las formas de conocimiento, incluidas las científicas/racionales, complejas/relacionales, constructivistas y otras. La agroecología desafía la lógica convencional y productivista de los sistemas alimentarios. Lo hace mediante la revalorización de los sistemas de conocimientos indígenas y tradicionales, que están inevitablemente ligados a lugares y relaciones sociales basadas en el territorio.

Con la categoría de territorio queremos argumentar que solo mediante el cese del acaparamiento de tierras y recursos, la defensa de los territorios indígenas y la construcción de territorios de campesinos, indígenas y trabajadores a través de una reforma agraria popular e integrada, se puede llevar a escala la agroecología. Como tal, las soluciones agroecológicas implican la transformación de las relaciones sociales asociadas a la tenencia de la tierra, lo que en la práctica significa la ruptura de las estructuras de poder de los terratenientes, que pueden adoptar formas agrarias, laborales, legales, económicas, políticas o culturales. Es por ello que la reforma agraria sigue siendo la política por excelencia de esta categoría, sin la cual la agroecología y la soberanía alimentaria no pueden escalarse. En las políticas territoriales también incluimos el acceso a ciertos 
medios como los sistemas de crédito público; los medios biológicos para las primeras etapas de la reconfiguración agroecológica; y la infraestructura rural. Interrumpir el poder terrateniente es solo el primer paso. La política agroecológica es también aquella que impide que los imperios alimentarios se afiancen, reduciendo el control que actualmente tienen en los supermercados, el establecimiento de precios y en las negociaciones comerciales internacionales.

Finalmente, elegimos la soberanía. La agroecología construye la soberanía alimentaria en todos los niveles, como queda claro en la declaración de Nyéléni (IFA, 2015), al poner la producción, la distribución y el consumo de alimentos en las manos de los pueblos. Al mismo tiempo, las políticas nacionales, locales y populares son necesarias para proteger los procesos agroecológicos ante la ofensiva del capital transnacional (McKay et al., 2014). Soberanía significa que la agroecología es entendida como parte de sistema alimentarios autónomos, en los cuales los actores sociales son libres de definir, construir y defender su cultura alimentaria, y protegerse de actores depredadores externos -tales como bancos, compañías mineras y circuitos de agronegocios- que podrían socavar sus culturas alimentarias.

Cada uno de estos tres principios se utiliza para analizar la política progresista en torno a la agroecología que ha surgido desde 1999 en América Latina y el Caribe.

\subsection{Saber}

En esta categoría se incluyen políticas que han promovido o apoyado procesos de formación agroecológica, intercambio de experiencias y saberes, investigación-acción, acompañamiento técnico a familias y comunidades productoras. Sobresale la Política Nacional Brasileña de Extensión Rural (PNATER) creada en 2004, que en el periodo 2010-2014 alcanzó a contar con un presupuesto de 600 millones de USD y beneficiar a aproximadamente 550 mil familias (Borsatto, 2018). También en Brasil, destaca la creación, desde 2003, de más de 167 cursos de tecnólogo y licenciado en Agroecología, y líneas y programas de doctorado en Agroecología (Schmitt et al., 2017); y en Venezuela, el Programa de Formación de Grado en Agroecología de la Universidad Bolivariana de Venezuela, con más de 2,000 egresados que son parte de las dinámicas agroecológicas del país (Domené et al., en esta obra).

En este grupo de políticas incluimos las de transición hacia la agroecología que apoyan con capacitación y coproducción de conocimientos agroecológicos, especialmente para la autonomía alimentaria. Entre los casos emblemáticos se encuentran el programa ProHuerta en Argentina con 464,527 huertas en funcionamiento (Patrouilleau, 2017), el programa Manos a la Siembra en Venezuela, y sobre todo, el Programa Nacional de Agricultura Urbana, Suburbana y Familiar del Instituto de Investigaciones Fundamentales en Agricultura Tropical (INIFAT) en Cuba. Este programa tiene más de un millón de personas vinculadas; genera más de 300 mil empleos; cuenta con 23 subprogramas en organopónicos, huertos intensivos y cultivos semiprotegidos, patios y parcelas familiares, proyectos municipales, y fincas suburbanas; está articulado con 8 ministerios y 16 instituciones; cuenta con una red de más de 7 mil 
centros de abonos orgánicos; y una red de 147 fincas municipales productoras de semillas. ${ }^{2}$

Cuba fue el país pionero en la región en implementar políticas públicas favorables a la agroecología como respuesta a la crisis originada por la caída del bloque socialista (Machín Sosa et al., 2010), cuando el país optó por implementar muchas ideas hasta entonces minoritarias de los científicos cubanos que recomendaban desvincular la producción agrícola de las tecnologías importadas. A lo largo de la década de 1990, Cuba masificó la agricultura urbana con pocos recursos externos, mientras la alimentación del país recayó sobre el sector campesino asociado, que nunca había perdido ciertas prácticas ancestrales, como la rotación de cultivos, el arado con buey y el uso de estiércoles y composta para mantener la fertilidad del suelo. La existencia de más de quince institutos de investigación agroecológica que existían antes de la crisis de los noventa fue crucial para la expansión de la agroecología en Cuba. Particularmente, sobresale el Fórum de Ciencia y Técnica del Consejo de Estado, y las universidades que actualmente hacen investigación situada en todas las provincias del país.

\subsection{Territorio}

Al hacer balance de la redistribución de la tierra, los logros han sido muy limitados. A pesar de que los gobiernos del Partido de los Trabajadores (PT) de Brasil, distribuyeron más de 51.2 millones de hectáreas a 721,442 familias (Sauer \& Mészáros, 2017), las tierras adjudicadas fueron públicas y en áreas marginales, buscando el menor impacto posible en los intereses latifundistas. La estrategia del gobierno de Evo Morales en Bolivia fue similar, pues para 2014 se habían distribuido 28.2 millones de hectáreas a 369,507 beneficiarios (Webber, 2017); aunque en realidad fueron programas de legalización y titulación de tierras que no afectaron los intereses de los terratenientes. En Venezuela, el caso es distinto, porque aunque gracias a la Ley de Tierras y Desarrollo Agrario se logró recuperar la importante cantidad de 6.34 millones de hectáreas y distribuir 117,224 cartas agrarias, ese resultado no se tradujo en un aumento de la superficie cultivada pues coincidió con una política económica enfocada a la obtención de rentas petroleras (Purcell, 2017). En Cuba, por el contrario, la reforma agraria de 2008 y 2012 sí favoreció la masificación de la agroecología del Movimiento Agroecológico Campesino a Campesino de la Asociación Nacional de Agricultores Pequeños (ANAP). Se trató de una política que entregó a campesinos 1.9 millones de hectáreas de tierras ociosas de las empresas estatales mediante la figura de "usufructuarios" (Vázquez et al., 2017).

También existieron en este conjunto de países líneas de créditos especiales a bajo interés, entre los cuales vale mencionar el Programa Nacional de Fortalecimiento a la Agricultura Familiar (PRONAF) en Brasil (Schmitt et al., 2017), los créditos a usufructuarios de la reforma agraria del Banco de Crédito y Comercio en Cuba (Vázquez et al., 2017), el crédito blando para productores del nuevo Ministerio de la Economía Familiar, Comunitaria, Cooperativa y Asociativa de Nicaragua, los préstamos para pequeños

2 Datos obtenidos por el INIFAT del Ministerio de Agricultura de Cuba. 
y medianos cacaoteros del nuevo Instituto de Economía Popular y Solidaria en Ecuador (Clark, 2017), y los créditos de la Empresa de Apoyo a la Producción de Alimentos (EMAPA) en Bolivia (Webber, 2017). Aunque en algunos casos estos créditos han desplazado a los prestamistas usureros que prevalecían, también han recibido la crítica que, salvo en Cuba, están dirigidos para agricultores con mayor capacidad de pago, y no promueven la agroecología, sino monocultivos del agronegocio.

Con respecto al acceso al agua vale la pena nombrar la nueva Constitución Política de Bolivia que establece el agua como bien común y el programa Un Millón de Cisternas Rurales en Brasil, para la captación y almacenamiento de agua lluvia, que ha permitido dinamizar huertos en zonas áridas (Schmitt et al., 2017). Para el acceso a las semillas es importante mencionar el Programa Nacional de los Recursos Genéticos en Cuba el cual estableció un sistema de abastecimiento de semillas para el programa de agricultura urbana, y en Venezuela la Ley de Semillas de 2016, que prohíbe los patentes, transgénicos y establece la semilla como patrimonio de los pueblos a servicio de la humanidad. En Cuba, dos programas insignia para la transición agroecológica con el Programa Nacional de Producción de Medios Biológicos, creado en 1988, y el Programa Nacional de Abonos Orgánicos y Biofertilizantes, en 1991; con ambos se descentralizó la producción de controladores biológicos de plagas -entomófagos y entomopatógenos-, mediante una red de más de 200 laboratorios al servicio del campesinado, que a su vez confluyeron con una serie de políticas del Estado que favorecieron la rápida evolución del Movimiento Agroecológico Campesino a Campesino ${ }^{3}$.

Así mismo son importantes de mencionar los programas de infraestructura rural, como el Programa de Apoyo a la Infraestructura en los Territorios Rurales (PROINF) en Brasil, y la inversión en caminos rurales que ha existido en la mayoría de estos gobiernos, lo que ha permitido disminuir los costos de transporte, reducir el poder de los intermediarios y acercar a las familias agricultoras con la población consumidora.

\subsection{Soberanía}

Brasil, con su Política Nacional de Agroecología y Producción Orgánica (PNAPO) de 2012, Nicaragua, con su Ley de Fomento a la Producción Agroecológica de 2011, y Uruguay con su Plan Nacional para el Fomento a la Producción con bases Agroecológicas, han sido los países que hasta hoy han promulgado leyes específicas y normativas para la agroecología. Sin embargo, en estos y otros países también se ha creado un marco legal favorable, como la Ley Orgánica de Seguridad y Soberanía Agroalimentaria y la Ley Orgánica de Salud Agrícola Integral en Venezuela, la Ley de Reparación Histórica de la Agricultura Familiar en Argentina, los sistemas Participativos de Garantía de la Calidad Orgánica en Brasil, así como leyes ambientales afines a la agroecología y legislación

\footnotetext{
3 Programa Nacional de Tracción Animal, Programa Nacional de Producción de Materia Orgánica, Programa Cultivo Popular del Arroz, Programa Nacional de Mejoramiento y Conservación de Suelos, Programa Nacional de Lucha contra la Desertificación y la Sequía, Programa Forestal Nacional, Programa de Mejoramiento Participativo de Plantas, Programa de Fincas Forestales Integrales (Machín Sosa et al., 2010).
} 
en torno al derecho a la alimentación (FreguinGresh, 2017). También han sido importantes las políticas restrictivas para el agronegocio, como la prohibición del glifosato en doce municipios de Argentina para hacer valer el principio de la precaución respecto a sustancias dañinas para la salud humana y la naturaleza.

Entre las experiencias locales, ninguna brilla tanto como la de Rio Grande do Sul y Belo Horizonte, donde se implementó el Programa de Adquisición de Alimentos (PAA) en 2003 y, posteriormente, el Programa Nacional de Alimentación Escolar (PNAE). Estas dos políticas tenían por objetivo comprar alimentos orgánicos/ agroecológicos con precios hasta un 30\% superior a los de los productos de la agronomía convencional, para escuelas públicas locales, programas de alimentación, bancos de alimentos, cocinas comunitarias, asociaciones caritativas y centros comunitarios (Schmitt et al., 2017). En Cuba, por su parte, existe facilidad de comercialización mediante precios fijos establecidos por el Ministerio de Finanzas y Precios, y existe un seguro estatal que cubre el 50\% de la prima - para viandas y granos. Las cooperativas, ${ }^{4}$ a las que están integradas los campesinos cubanos, venden al agrocentro estatal, que distribuye a otros lugares de Cuba; aunque también ellas cuentan con puntos de venta directa (Chan \& Freyre, 2010).

Nicaragua ha logrado en la última década entre el 80 y $90 \%$ de su autosuficiencia alimentaria, aumentando la producción de arroz del 30\% del consumo en 2006 a más del 70\% en 2017 (NúñezSoto, 2018). Sin embargo, el poder terrateniente ha permanecido fuerte, y cuando, debido a su propia crisis, Venezuela dejó de comprar carne de vacuno nicaragüense en marzo de 2018, la oligarquía terrateniente dirigió un esfuerzo prolongado y violento para derrocar el gobierno que hasta ese momento le había provisto de una lucrativa oportunidad de negocio con las exportaciones de carne de vacuno (Dada, 2018). Nicaragua fue en 2017 el único país centroamericano con una balanza comercial positiva con los Estados Unidos (Oficina del Representante Comercial de Estados Unidos, 2018), sin duda, uno de los factores que alimentaron los esfuerzos del cambio de régimen desde fuera del país.

Los logros y avances en estas políticas son evidentes. Sin embargo, es importante destacar algunas de sus mayores dificultades y obstáculos:

1. Solo en Cuba se puede argumentar que existe un esfuerzo por articular políticas a nivel nacional para transformar el sistema alimentario mediante la agroecología (Chan \& Freyre 2010). Sin embargo, hay voces dentro del sector estatal que perciben la agroecología como una alternativa provisional mientras se restablecen las relaciones comerciales. (Altieri \& Funes-Monzote, 2012).

2. En los demás casos, las políticas agroecológicas han sido pequeñas islas en un mar de políticas para el agronegocio. Brasil, a pesar de los muchos problemas agroecológicos de los gobiernos del PT, al mismo tiempo se convirtió en el mayor consumidor global de agroquímicos, y el segundo en superficie cultivada con cultivos genéticamente modificados (Schmitt et al., 2017).

\footnotetext{
${ }^{4}$ Las figuras: Cooperativas de Producción Agropecuaria (CPA) y Cooperativas de Crédito y Servicio (CCS), creadas por el Estado, fueron fundamentales para configurar una estructura nacional articulada a la ANAP en torno a la agroecología (Machín Sosa et al., 2010).
} 
3. Los logros han sido muy vulnerables ante los cambios de régimen político. Por ejemplo, con el golpe de Estado del gobierno neoconservador de Temer en 2016, en Brasil "se cerró el Ministerio de Desarrollo Agrario dedicado a la Reforma Agraria y agricultura familiar, y se cortaron los recursos para las compras públicas y la agroecología" (Schmitt et al., 2017, p. 387). Bolsonaro, por su parte, prometió cerrar las escuelas del Movimiento de los Trabajadores Rurales sin Tierra (MST) y declarar al movimiento como "organización terrorista", mientras que en Argentina el gobierno de Macri desmanteló en 2018 la recién creada Secretaría de Agricultura Familiar.

4. Las políticas que fomentan los circuitos cortos se burocratizaron a tal nivel que terminaron por establecer listas de requisitos, documentos, mecanismos de control y normas de calidad totalmente desajustadas a la filosofía agroecológica y ajenas a la economía campesina (Freguin-Gresh, 2017; Schmitt et al., 2017).

5. La legislación ha conjugado la agroecología con la agricultura orgánica, y por tanto se basa en la sustitución de insumos (Rosset \& Altieri, 1997) y no en el rediseño de parcelas y paisajes rurales.

\section{Agroecología y estado del Estado}

Después de hacer un balance de las políticas públicas de agroecología en América Latina y el Caribe, consideramos necesario hacer una reflexión sobre la situación contemporánea del Estado y las posibilidades reales de lo que se puede hacer desde sus instituciones en nuestros días. Lo hacemos, sin embargo, no como un ejercicio en el que nos ponemos los lentes del Estado -como si estuviéramos allá arriba-, sino más bien como un análisis para orientar los esfuerzos de los movimientos agroecológicos para juzgar cuándo y en qué medida deberían esforzarse por ganar reformas institucionales para territorializar la agroecología.

Durante dos décadas después del final de la Guerra Fría, a excepción de Cuba, hubo un acuerdo tácito entre las fuerzas de la izquierda y de la derecha en la política latinoamericana. El arreglo consistía en que los movimientos de izquierda honrarían la democracia burguesa -buscando el poder político a través de las elecciones y protegiendo la propiedad privada-a cambio de que no se utilizaran medios militares para exterminarlos y permitirles presentar su plataforma a los votantes (Núñez-Soto, 2018). Según Vergara-Camus \& Kay (2017) cuando la izquierda obtiene el triunfo electoral, si bien incorpora activistas de los movimientos sociales a la burocracia institucional y adoptan algunas de sus ideas, no puede transformar radicalmente las relaciones que estructuran todo el sistema. Ello ocurre porque los gobiernos progresistas en realidad no emergen como clase dominante, $y$ en tal sentido se ven obligados a hacer acuerdos y coaliciones programáticas con fuerzas históricamente opositoras para ganar las elecciones y tener gobernabilidad, por lo que tienen que domesticar las banderas más radicales una vez que se institucionalizan las agendas en la burocracia estatal (Rosset, 2018).

La experiencia de los gobiernos progresistas en América Latina muestra que, aparte de Cuba y Venezuela, ninguno rompió las estructuras del poder terrateniente; por el contrario, bajo su gestión, los grandes terratenientes se reagruparon formando alianzas con el capital transnacional. Las coaliciones 
de izquierda y centroizquierda argumentaron que controlaban el gobierno pero no el Estado (GarcíaLinera, 2012), y como tal, la oposición de las clases burguesas, rentistas y oligárquicas a las políticas redistributivas necesitaría ser "suavizada", al garantizarles inversión en infraestructura pública, mayores niveles de estabilidad social y facilitar la expansión del capital en ciertas áreas estratégicas. En este sentido, los regímenes progresistas entregaron exactamente lo que el capitalismo necesitaba: una política más aceptable, estabilidad económica y una nueva infraestructura para la privatización futura. Se está volviendo evidente que una o dos décadas de gobierno progresista favorecen la estabilidad general del sistema capitalista.

Creemos que los movimientos populares latinoamericanos están interpretando esta situación de manera distinta. Aunque no son necesariamente antagónicos entre sí, dos posiciones emergentes sugieren estrategias diferentes a largo plazo. Ambos comienzan con el reconocimiento de que los gobiernos de centro-izquierda generalmente no han logrado el cambio estructural, e incluso "hasta cierto punto, sentaron las bases para el retorno de la Derecha, al no resolver las contradicciones estructurales y políticas del país, y al facilitar el acceso extraordinario de los agronegocios y del capital financiero a las zonas rurales y a los programas de gobierno" (Pinheiro, 2018, p. 1). Sin embargo, a partir de este momento, las interpretaciones difieren. ¿Es el Estado intrínsecamente regresivo y represivo, sin importar quién ejerza su poder? $¿ \mathrm{O}$ es que el Estado tuvo alguna vez el potencial de transformar las estructuras económicas -como en Cuba-, pero lo ha perdido en los últimos treinta años como resultado del capitalismo globalizado? ¿O es que el Estado todavía tiene el potencial de redistribuir la riqueza, defender los bienes comunes y los territorios ancestrales, e incluso descolonizar la sociedad latinoamericana mediante la transformación de la sociedad pública y redefinir las prioridades nacionales?

Estas dudas teóricas se traducen inmediatamente en correlaciones políticas: ¿deberían los gobiernos de izquierda haber roto las relaciones con la oligarquía local, los inversionistas transnacionales y los Estados Unidos, inmediatamente después de ser elegidos y en su lugar decretar la soberanía alimentaria? ¿Deberían haber tomado ventaja del momento en que tuvieron que nacionalizar activos de las corporaciones y reformar el sistema político corrupto que, en última instancia, orquestó contra ellos los golpes de Estado? ¿Deberían los movimientos sociales rurales haber evitado forjar alianzas con la clase obrera urbana para apoyar a los candidatos de izquierda, en vez de rechazar la política "posneoliberal" como una farsa? ¿La situación actual exige más autonomía, o llama a un frente popular más fuerte contra el fascismo? En resumen, la situación actual en América Latina exige una profunda reflexión sobre estrategia y táctica de soberanía alimentaria, pragmatismo, alianzas, reformas y revolución.

Resumiremos brevemente lo que consideramos dos de las tendencias más importantes de los movimientos sociales rurales: una que llamamos "autonomista" y otra que denominamos "soberanista". Aunque no sean etiquetas precisas, la perspectiva autonomista puede ser personificada por el movimiento zapatista en el sur de México, mientras que la soberanista por la tradicional posición de izquierda del MST en Brasil.

La posición autonomista refleja una concepción que rechaza colocar el poder del Estado en el centro 
de las estrategias de los movimientos sociales para cambiar la realidad. En cambio, se centra en la libre determinación y la democratización como procesos ascendentes. Esta posición es muy crítica con los intentos de involucrar al Estado como socio en la territorialización agroecológica. La preocupación es que la participación en la institucionalización de la agroecología podría servir a las tecnologías de los gobiernos para mantener una agricultura dual -el agronegocio en coexistencia pacífica con la agricultura campesina ahora renombrada como agroecológica- mientras que los movimientos agroecológicos quedan subsumidos por la lógica de las normativas, programas y proyectos de una burocracia institucional acoplada a las fuerzas del mercado.

Los autonomistas ven un inmenso riesgo de ser incorporados a las reglas de juego establecidas; incluidos en el marco de poder instituido, teniéndose que mover en un sistema cuyo fin es la preservación de los intereses de la clase dominante (Rancière, 1999; Negri, 1999). Esta posición considera que existe el riesgo de que la agroecología, en lugar de que sea un poder destituyente -capaz de hacer inoperante el sistema ante el cual se revela- se convierta en un poder que mantenga operantes las formas de poder del sistema políticoeconómico constituido (Agamben, 2014). Los autonomistas advierten sobre la posibilidad de que la insitucionalización de la agroecología, y las políticas públicas subyacentes, devengan serviles a las lógicas de acumulación de capital, provocando que la agroecología sea fagocitada por el enemigo que se quería combatir. Esta posición considera que la mejor estrategia para reemplazar los agronegocios por la agroecología es un proceso de educación agroecológica autónoma y la ampliación horizontal a través de redes.

La posición soberanista, en cambio, ve a las empresas transnacionales como el principal enemigo $\mathrm{y}$ exige que las personas aprendan a gobernarse a sí mismas, pero también a gobernar territorios y a ejercer la plena soberanía, con el fin de controlar el poder corporativo. Desde este punto de vista, el carácter del Estado depende de que la clase social domine a las demás; solo la intervención activa del Estado, en respuesta a una movilización popular permanente y masiva, es capaz de detener los acuerdos comerciales y la apropiación de recursos del capital transnacional. Cuando los movimientos paran físicamente la instalación de equipos mineros u ocupan granjas, recurren a marcos y mecanismos legales para evitar enfrentamientos violentos directos y muertes. La base de estas estrategias legales es la expectativa de que el Estado no permitirá que los poderes capitalistas cometan violaciones masivas de derechos humanos.

En este debate hay buenas razones de ambas partes. Del lado autonomista pueden anticiparse varios riesgos con la institucionalización de la agroecología. De hecho, con el retorno a los regímenes ortodoxos que transfieren al Estado las funciones del sector privado, existe un enorme riesgo de que la institucionalización de la agroecología termine siendo un aliado de las inversiones. En particular vale la pena mencionar el caso de las industrias extractivas. Los esquemas de pagos por compensación del daño por la acción de grandes empresas -minería, hidrocarburos, presas, eólicas-, o pago por servicios ambientales tipo REDD+, pueden terminar dirigidos hacia la financiación de proyectos agroecológicos en alianzas públicoprivadas. La agroecología se pone de moda (Giraldo 
$\&$ Rosset, 2018) en un entorno crecientemente neoliberal y neoconservador, y el boom de dinero que puede llegar como transferencia para conservación y proyectos productivos derivados de la compensación por la destrucción de ecosistemas en otros territorios no puede subestimarse. Las políticas públicas y el financiamiento para la agroecología pueden ser una oportunidad para lavar proyectos extractivistas, no solo para tener viabilidad jurídica -las compensaciones para mitigación por cambio de uso de suelo es obligación en muchos países-, sino legitimidad al adoptar un disfraz ambiental y un rostro socialmente responsable.

La agroecología asociada a la agricultura climáticamente inteligente, es bienvenida por las corporaciones más grandes del mundo. El reciente interés de incluir la agroecología en la política pública puede explicarse parcialmente por la necesidad del agrocapitalismo de crear, o ampliar, nuevas fuentes de negocios, como la industria de insumos orgánicos industriales, los monocultivos orgánicos para nichos de exportación, lucrar con la venta de bonos de carbono, agroecoturismo, biocomercio, al mismo tiempo de restablecer las condiciones de producción (O'Connor, 1998) degradadas por las tecnologías de la revolución verde (Giraldo \& Rosset, 2018; Giraldo, 2019).

Una advertencia más del lado autonomista es acerca de los riesgos inherentes al flujo de recursos que vendrán para financiar programas, proyectos y préstamos para la agroecología y que han sido anunciados con el programa global Scaling up Agroecology Initiative ${ }^{5}$ de la FAO. Como se ha visto en los casos más autónomos, la austeridad como principio de trabajo es virtud, y por el contrario, como suele ocurrir en los clásicos proyectos del desarrollo, el exceso de dinero corrompe los procesos. La austeridad impide el clientelismo, el corporativismo y el apego al poder, y fomenta, en cambio, la imaginación política, estimula el florecimiento de la reciprocidad, el apoyo mutuo, y la solidaridad para construir caminos por fuera del mundo del dinero y la economía. La sencillez evita que se creen relaciones estimuladas por los salarios de los proyectos, que surjan desigualdades en el modo de vida entre quienes devengan recursos de los proyectos y el resto de los campesinos. Hemos ya sido testigos por mucho tiempo de que los proyectos y programas políticos suelen ser verdaderas escuelas de consumo que crean dependencia respecto del dinero (Baschet, 2015), que destejen las relaciones comunitarias basadas en otro tipo de valores -como la gratuidad y el placer del servicio- las cuales no pasan por la lógica del interés monetario (Timmermann \& Félix, 2015).

Además, incluso en los mejores casos de políticas agroecológicas, existen riesgos asociados a la creación de una población "beneficiaria". Aunque si bien una buena política pública en general tiene un impacto desmovilizador, este efecto cobra toda su agudeza cuando los gobiernos que producen la política buscan desmovilizar, acomodar o cooptar a los movimientos. El propio Estado crea la imagen de que el movimiento se ha vuelto redundante en la medida en que sus instituciones ya están satisfaciendo las exigencias de la base (McKay et al., 2014). Como tal, los movimientos necesitan mostrar extrema prudencia al decidir cuándo "sacar provecho" de su movilización y consolidarlo como reformas institucionales. Si las buenas políticas

${ }^{5}$ www.fao.org/3/I9049EN/i9049en.pdf 
desmovilizan completamente al movimiento, se hace mucho más difícil reaccionar a los vientos políticos cambiantes.

Sin embargo, también es necesario prestar atención a la posición soberanista. No participar en la institucionalización de la agroecología podría impedir que se modifique aunque sea parcialmente la razón de Estado en torno a la política agroalimentaria, apoyando de manera indirecta a que se gesten aún más obstáculos para que la agroecología pueda territorializarse. Conquistar ciertos espacios es posible para facilitar algunos aspectos como se mostró en las políticas que se han logrado hasta el momento, u otras que podrían conquistarse mediante una adecuada correlación de fuerzas del movimiento agroecologista y las élites económicas que suelen dominar el poder político. El Estado no es un agente monolítico y sin fisuras. Es justamente su propia condición de contradicción permanente la que permite abrir brechas, rupturas, intersticios dentro del mismo sistema global de poder. Cuando concurre la suficiente correlación de fuerzas derivadas de la organización social, pueden abrirse esos espacios y lograr que se efectúen algunas políticas antagónicas al proyecto de las élites dominantes (Boneti, 2006). No obstante, es necesario todavía preguntarse cómo abrir esas grietas sin que los movimientos pierdan la visión de los objetivos; sin que la agenda estatal se coma al movimiento.

\section{Conclusión: ¿reformismo o revolución agroecológica?}

En los últimos años del siglo XIX, Eduard Bernstein (1993 ([1889]) abrió un agudo debate sobre el papel de la socialdemocracia en la construcción del socialismo. Su famosa tesis aseguraba que era posible cumplir los objetivos del movimiento obrero sin tener que recurrir a la revolución, apelando a reformas paulatinas en el marco de las instituciones del Estado. La estrategia, según Bernstein, consistía en llevar a cabo reformas graduales y cambios cualitativos en las relaciones capitalistas de producción a través de las instituciones políticas del régimen capitalista para anegar lentamente de acuerdo con los fines del socialismo (Steger, 2006). Rosa Luxemburgo controvirtió esas ideas en su famoso trabajo Reforma o revolución (2006 [1900]), cuestionándolas por haber abandonado el análisis de clase y ofrecer soluciones que solo servirían a la perpetuación del orden burgués. Este antiguo debate cobra vigencia en las discusiones del progresismo latinoamericano de inicios del siglo XXI, pues la historia ha mostrado que no pueden realizarse cambios radicales -como los que requiere la transformación del sistema agroalimentario globalizado- respetando la institucionalidad y el statu quo vigente.

La pregunta para el movimiento agroecológico es si aspiramos a un reformismo del modelo agroalimentario, o si, por el contrario, nuestra lucha es por una revolución campesina de base agroecológica que transforme radicalmente el sistema instituido (Levidow et al., 2014). Lo que hemos aprendido de los regímenes progresistas, como los que han llegado a ocupar el gobierno en América Latina desde inicios del nuevo milenio, es que, en esencia, han tenido negada la posibilidad de ir a contravía de la reproducción del capital, lo cual es particularmente evidente en los temas agrarios, pues lo que ha ocurrido en la región ha sido una 
expansión sin antecedentes de los agronegocios, ${ }^{6}$ acompañados por algunos cambios menores en la estructura agroalimentaria. Esto nos enseña que contra la "hidra capitalista" no podemos seguir apuntando el machete a una sola de sus cabezas.

¿Cuál debe ser la perspectiva de los movimientos agroecológicos, en este momento histórico de contrarrevolución y de ascenso de la extrema derecha? Tal vez la elección de si participar o no en las instituciones es una falsa dicotomía. Creemos que es necesario abrir una lucha en varios frentes, aunque pueda sonar contradictorio. Mientras exista el Estado es necesario disputarlo para abrir ciertas grietas. En algunos aspectos como el acceso a los medios de producción, el Estado constituye un ente al que no podemos renunciar en el proceso de construcción de la hegemonía. Por eso cuando existen regímenes afines es necesario cooptarlos, permearlos, conspirar por dentro, crear sentido común, ganar espacios para las propuestas de transformación social gracias a los aliados dentro de las estructuras de poder. Pero también saberse distanciados como entes críticos de la burocracia estatal.

Esto, en otros términos, significa repensar las estrategias descentrando al Estado: sacándolo del centro, marginalizándolo, lo que quiere decir que no podemos concentrarnos en el Estado, pero tampoco lo podemos ignorar. En toda América Latina, las comunidades campesinas desplazadas por tractores y guardias armados no tienen más remedio que recurrir a las instituciones. Sin protección legal o derechos en los que basar sus reclamos, las comunidades agroecológicas tienen muy pocas opciones para activar campañas en los medios de comunicación y redes de solidaridad ante su difícil situación.

Ignorar las políticas públicas también significa entregarlas a las corporaciones que intentan imponer su versión de agroecología como herramienta del capitalismo verde. Más bien, los movimientos agroecológicos pueden y deben desarrollar la capacidad de crear y defender sus saberes, sus territorios y su soberanía, construyendo sus propias instituciones y haciendo uso del Estado cuando y solo cuando dicho uso fortalezca concretamente los procesos de emancipación, autonomía y autodeterminación de las bases.

De hecho, las políticas implementadas por Cuba y por los gobiernos progresistas en la región enseñan que las acciones institucionales que deben buscarse son aquellas que faciliten ciertas condiciones para que la agroecología pueda practicarse y expandirse, pero sin que esas acciones generen dependencias o eclipsen los procesos ante cambios de administraciones. En otras palabras, es aceptable que exista algún grado de heteronomía que complemente procesos sociales en curso y que abra la posibilidad a otros nuevos, sin que las acciones institucionales aplaquen el dinamismo de las acciones colectivas más autónomas. El objetivo de las políticas deseables que pueden gestarse gracias a la presión de la sociedad civil, consiste en abrir espacios y liberar ciertos recursos para que los actores organizados puedan usarlos con base en sus acuerdos colectivos y horizontes culturales. La idea es que el acompañamiento de agentes externos fomente las relaciones espontáneas entre personas, y de ese modo se distribuya el poder, se aliente el acceso a saberes

\footnotetext{
${ }^{6}$ El caso más dramático lo constituye "la república de la soya" en Suramérica. Se trata de una superficie que en Brasil, Argentina, Uruguay, Paraguay y Bolivia creció de 17 a 46 millones de ha entre 1990 y 2010, y en la que se deforestaron 20 millones de ha entre 2000 y 2010 (WWF, 2014).
} 
y bienes comunes, y haya una transición paulatina hacia la autonomía de individuos y comunidades.

Creemos que la financiación pública para la búsqueda de algunos de esos objetivos no debe rechazarse y que, como enseñan algunos casos emblemáticos como los descritos, puede dársele la bienvenida a políticas específicas para el escalamiento de la agroecología. Nos referimos a los apoyos estatales para: 1) escuelas de formación agroecológica lideradas por movimientos y organizaciones rurales -véase Rosset et al., en este volumen-; 2) procesos horizontales de intercambio tipo Campesino a Campesino -véase Val et al. y Khadse \& Rosset, en este volumen-; 3) mercados campesinos situados, y territoriales; 4) programas de compras públicas de alimentos producidos de manera agroecológica; 5) reforma agraria; 6) apoyo para la recuperación y el fortalecimiento de los sistemas locales de semillas -véase García et al., en este volumen-; 7) liberación de fondos para la investigación en agroecología; 8) programas públicos de enseñanza básica para la agroecología -véase Morales y Ferguson, en este volumen- y carreras universitarias asociadas a cambios en el currículo de la agronomía y otras carreras agropecuarias (véase Domené et al., en este volumen).

Todo esto es aceptable y sin duda ayuda a las transiciones agroecológicas. Sin embargo, es la política de abajo la que debe concentrar la mayor parte de los esfuerzos, teniendo claro que las fisuras que pueden abrirse en el Estado, el gobierno y las instituciones, son únicamente complemento de la construcción colectiva por la autodeterminación y la autonomía de las organizaciones campesinas y populares. No podemos menospreciar la capacidad estructurante de la política que se hace desde abajo mediante la autoorganización, la autogestión, y la revitalización de las relaciones y la regeneración de los ámbitos comunitarios. En términos de Spinoza (2001), es la potentia-habilidad interior-y no tanto la potestas -poder exterior- el elemento que debe fortalecerse en las luchas antisistémicas.

Otorgar demasiado poder al Estado mediante la búsqueda de políticas públicas para la masificación de la agroecología, puede ser contraproducente si es un medio para capturar la potentia colectiva construida por los ensayos heterárquicos de poder que se han hecho desde abajo. Por eso las discusiones sobre el escalamiento de la agroecología deben salir del tono estadocentrista que han tomado en sus inicios. Los procesos sociales horizontales de la agroecología, y en especial el Campesino a Campesino, han mostrado con mucha elocuencia que es posible reavivar las riquezas relacionales, regenerar la red de relaciones humanas, y revitalizar saberes tradicionales, movilizando la capacidad de las comunidades rurales y suburbanas de usar los recursos disponibles, como semillas, técnicas, herramientas y saberes. Estas experiencias son una prueba de la potencialidad que tiene rehabilitar ámbitos comunitarios, y las ventajas de las estructuras relacionales basadas en la participación masiva y la creatividad colectiva (Giraldo, 2019).

Lo anterior es solo una manera de decir que la masificación de la agroecología es radicalmente distinta a la lógica de los proyectos, porque cambia el sentido de construcción de procesos, pues se hace lentamente, ${ }^{7}$ poco a poco, su crecimiento

\footnotetext{
${ }^{7}$ Recordamos los principios de Campesino a Campesino: empezar despacio y en pequeño, limitar la introducción de tecnologías, experimentar en pequeña escala.
} 
es rizomático y a largo plazo, muy distinto a la lógica de los periodos gubernamentales y los ciclos de financiación de proyectos. Las transiciones agroecológicas son procesos de larga duración y demandan continuidad. Esta lógica procesual, lenta, continua y cualitativa tiene un ritmo diferente a las agendas de los gobiernos, los cuales deben regirse por indicadores y resultados cuantitativos, marcos jurídicos estrictos, contrataciones de personal profesional para labores específicas, y ciclos de financiación cortos.

\section{Referencias}

Agamben, G. What is a destituent power? Environment and planning D. Society and Space, 32(1), 65-74, 2014. doi: $10.1068 / \mathrm{d} 3201$ tra

Altieri, M.; Funes-Monzote, F. The paradox of cuban agriculture. Monthly Review, 63(8), 23-33, 2012. doi:10.14452/MR-063-08-2012-01_3

Altieri, M. A.; Toledo, V. M. The agroecological revolution in Latin America: rescuing nature, ensuring food sovereignty and empowering peasants. Journal of Peasant Studies, 38(3), 587-612, 2011. doi:10.1080/03066150.2011.582947

Andermann, J. Turn of the tide? Cultural critique and the new right. Journal of Latin American Cultural Studies, 27(1), 1-3, 2018. doi: 10.1080/13569325.2017.1420635

Bähre, E.; Gomes, F. Humiliating the Brazilian poor: the iconoclasm of former president Lula. Anthropology Today, 34(5),10-15, 2018. doi:10.1111/1467-8322.12459

Baschet, J. Adiós al capitalismo: autonomía, sociedad del buen vivir y multiplicidad de mundos. Madrid: Ned ediciones, 2015.

Bello, W. Counterrevolution, the countryside and the middle classes: lessons from five countries. Journal of Peasant Studies, 45(1), 21-58, 2018. doi: 10.1080/ 03066150.2017 .1380628
El único camino que queda es el largo. Como el estratega militar Liddell Hart (1991[1954]) lo dijo: "En estrategia, el camino más largo puede ser el más corto a casa". Solo la práctica activa y la constancia en los métodos de organización comunitaria basados en métodos agroecológicos, diálogo, luchas locales y la construcción de liderazgo, pueden crear el tipo de movimientos de base sólidos que pueden cambiar el equilibrio de fuerzas. Aunque más lento de lo que nos gustaría, es la única forma posible de no apelar al reformismo, sino a la revolución.

Bernstein, E. Bernstein: the preconditions of socialism. Cambridge: Cambridge University Press, 1993 [1889].

Boneti, L. W. Politicas públicas por dentro. São Geraldo: Editora Unijuí, 2006.

Borón, A. América Latina en la geopolítica del imperialismo. México: CEIICH, 2014.

Borsatto, R. Brazilian experience in rural extension reform: challenges of a pluralistic and participatory policy addressing family farming. São Carlos: Inédito, 2018.

Chan, M. L.; Freyre, E. F. Atando cabos. La agricultura Cubana: contratiempos, reajustes y desafíos. La Habana: Oxfam, 2010.

Chomsky, N. Dominance and its dilemmas. Boston Review, 28(5), 2002. Disponible en: http://bostonreview.net/ archives/BR28.5/chomsky.html

Ciccariello-Maher, G. Building the commune: Insurgent government, communal state. The South Atlantic Quarterly, 113(4), 791-806, 2014. doi: 10.1215/00382876-2803657

Clark, P. Neo-developmentalism and a "vía campesina" for rural development: unreconciled projects in Ecuador's citizen's revolution. Journal of Agrarian Change, 17(2), 348-364, 2017. doi: 10.1111/joac.12203 
CLOC - Coordinadoria Latinoamericana de Organizaciones del Campo. Declaración final. In: VI Congreso de la Coordinadora Latinoamericana de Organizaciones del Campo-La Vía Campesina. Buenos Aires - AR, 10-17 abr., 2015. Disponible en: $<$ http://www.cloc-viacampesina.net/ congresos/vi-congreso $>$. Acceso en: oct., 2018.

Dada, C. Los enmascarados son de los dos bandos. El Faro, 2018. Disponible en: <https://elfaro.net/es/201807/ centroamerica/22202/“Los-enmascarados-son-de-losdosbandos".htm>. Acceso en: nov., 2018.

Escobar, A. Latin America at a crossroads: Alternative modernizations, post-liberalism or postdevelopment? Cultural Studies, 24(1), 1-65, 2010. doi: 10.1080/09502380903424208

Fernández, M.; Williams, J.; Figueroa, G.; Graddy-Lovelace, G.; Machado, M.; Vásquez, L.; Pérez, N.; Casimiro, L.; Romero, G.; Funes-Aguilar, F. New opportunities, new challenges: harnessing Cuba's advances in agroecology and sustainable agriculture in the context of changing relations with the United States. Elementa Science of Anthropocene, 6(1), 76, 2018. doi: 10.1525/elementa.337

Freguin-Gresh, S. Agroecología y agricultura orgánica en Nicaragua. Génesis, institucionalización y desafíos. En: Sabourin, E. P. et al. (Orgs.). Politicas públicas a favor de la agroecología en América Latina y El Caribe. Brasilia: FAO, Red PP-AL, p. 174-195, 2017.

García-Linera, Á. Las tensiones creativas de la revolución: la quinta fase del proceso de cambio. La Paz: Presidencia de la Asamblea Legislativa Plurinacional, 2012.

Giraldo, O. F. Political ecology of agriculture. Agroecology and post-development. Cham: Springer, 2019. doi: 10.1007/978-3-030-11824-2

Giraldo, O. F.; Rosset, P. M. Agroecology as a territory in dispute: between institutionality and social movements. The Journal of Peasant Studies, 45(3), 545-564, 2018. doi: 10.1080/03066150.2017.1353496

Gliessman, S. Scaling-out and scaling-up agroecology. Agroecology and Sustainable Food Systems, 42(8), 841-842, 2018. doi: 10.1080/21683565.2018.1481249
Gudynas, E. Debates sobre el desarrollo y sus alternativas en América Latina: una breve guía heterodoxa. En: Lang, M.; Mokrani, D. (Orgs.). Más Allá del Desarrollo. Quito: Ediciones Abya Yala, p. 21-53, 2011.

Holt-Giménez, E. Campesino a campesino: voices from Latin America's farmer to farmer movement for sustainable agriculture. Oakland: Food First Books, 2006.

IFA - International Forum for Agroecology. Declaration of Nyéléni. Sélingué, Mali, 27 feb., 2015. Disponible en: $<$ https://nyeleni.org/IMG/pdf/DeclNyeleni-en.pdf $>$. Acceso en: oct., 2018.

Katz, C. Las disyuntivas de la izquierda en América Latina. Buenos Aires: Ediciones Luxemburg, 2008.

Klein, N. The shock doctrine. New York: Metropolitan Books, 2007.

Korybko, A. Hybrid wars: the indirect adaptive approach to regime change. Moscú: Universidad Rusa de la Amistad de los Pueblos, 2015.

Levidow, L.; Pimbert, M.; Vanloqueren, G. Agroecological research: conforming-or transforming the dominant agro-food regime? Agroecology and Sustainable Food Systems, 38(10), 1127-1155, 2014. doi: 10.1080/21683565.2014.951459

Liddell Hart, B. H. Strategy. London: Meridian, 1991 [1954].

Luxemburg, R. Reform or revolution and other writings. Chelmsford: Courier Corporation, 2006 [1900].

LVC - La Vía Campesina. Small scale sustainable farmers are cooling the earth. Jakarta: Views, 2009. Disponible en: $<$ https://viacampesina.net/downloads/PAPER5/EN/paper5EN.pdf>. Acceso en: oct., 2018.

LVC - La Vía Campesina. UN Human Rights Council passes a resolution adopting the peasant rights declaration in Geneva, 2018. Disponible en: <https://viacampesina.org/ en/un-human-rights-council-passes-a-resolution-adoptingthe-peasant-rights-declarationin-geneva/>. Acceso en: oct., 2018 .

Machín Sosa, B.; Roque Jaime, A.; Ávila-Lozano, D. R.; Rosset, P. M. Revolución agroecológica: el Movimiento de 
Campesino a Campesino de la ANAP en Cuba. La Habana: ANAP, 2010.

McCune, N. Family, territory, nation: post-neoliberal agroecological scaling in Nicaragua. Food Chain, 6(2), 92-106, 2017. doi: 10.3362/2046-1887.2016.008.

McKay, B.; Nehring, R.; Walsh-Dilley, M. The 'state' of food sovereignty in Latin America: political projects and alternative pathways in Venezuela, Ecuador and Bolivia. Journal of Peasant Studies, 41(6), 1175-1200, 2014. doi: 10.1080/03066150.2014.964217

Mier y Terán C., M. G.; Giraldo, O. F.; Aldasoro, M.; Morales, H.; Ferguson, B.; Rosset, P. M.; Khadse, A.; Campos, C. Bringing agroecology to scale: key drivers and emblematic cases. Agroecology and Sustainable Food Systems, 42(6), 637-665, 2018. doi: 10.1080/21683565.2018.1443313

Mora, F. Don't focus on regime change in Venezuela. Foreign Affairs, 2018. Disponible en: $<$ https://foreignpolicy. com/2018/09/04/aftermaduro-in-venezuela-regimechange/>. Acceso en: oct., 2018.

Negri, A. Insurgencies: constituent power and the modern state. Minneapolis: University of Minnesota Press, 1999.

Nicholls, C. I.; Altieri, M. A. Pathways for the amplification of agroecology. Agroecology and Sustainable Food Systems, 42(10), 1170-1193, 2018. doi: 10.1080/21683565.2018.1499578

Núñez-Soto, O. ¿Quién produce la riqueza en Nicaragua? Managua: CIPRES, 2018.

O’Connor, J. R. Natural causes: essays in ecological marxism. New York: Guilford Press, 1998.

Office of the US Trade Representative. Resource Center, Western Hemisphere, Nicaragua, 2018. Disponible en: $<$ https://ustr.gov/countries-regions/americas/>. Acceso en: oct., 2018.

Parmentier, S. Scaling-up agroecological approaches: what, why and how? Belgium: Oxfam Solidarity, 2014. Disponible en: $<$ https://www.oxfamsol.be/fr/scalingagroecologicalapp roacheswhatwhyand-how $>$. Acceso en: oct.,2018.

Patrouilleau, M. M.; Martínez, L. E.; Cittadini, E.; Cittadini, R. Políticas públicas y desarrollo de la agroecología en Argentina. In: Sabourin, E. P et al. (Orgs.). Políticas públicas a favor de la agroecología en América Latina y El Caribe. Brasilia: FAO, Red PP-AL, p. 20-43, 2017.

Pinheiro, L. Dilemmas of peasant social movements faced with the dichotomy between progressive governments and the rise of the new right in Latin America: the case of Brazil. In: Working paper at Emancipatory Rural Politics Initiative: authoritative populism and the rural world. The Hague, 10 mar., 2018. Disponible en: https://www.iss.nl/ sites/corporate/files/201803/ERPI\%20CP\%2026_Barbosa. pdf. Acceso en: oct., 2018.

Purcell, T. F. The political economy of rentier capitalism and the limits to agrarian transformation in Venezuela. Journal of Agrarian Change, 17(2), 296-312, 2017. doi: 10.1111/joac.v17.2

Rancière, J. Disagreement: politics and philosophy. Minneapolis: University of Minnesota Press, 1999.

Riggirozzi, P.; Tussi, D. The rise of post-hegemonic regionalism in Latin America. En: Riggirozzi, P.; Tussi, D. (Orgs.). The rise of post-hegemonic regionalism: the case of Latin America. London: Springer, p. 1-16, 2012.

Rosset, P. M.; Benjamin, M. The greening of the revolution. Fort Lauderdale: Ocean Press, 1994.

Rosset, P. M. Moving forward: Agrarian reform as a part of food sovereignty. En: Rosset, P. M.; Patel, R.; Courville, M. (Orgs.). Promised land: competing visions of agrarian reform. Oakland: Food First Books, p. 301-321, 2006.

Rosset, P. M. América Latina y la conciliación de clases. México: La Jornada. Disponible en: $<$ https://www.jornada. com.mx/2018/08/19/opinion/022a1mun>. Acceso en: oct., 2018 .

Rosset, P. M.; Altieri, M. A. Agroecology versus input substitution: a fundamental contradiction of sustainable agriculture. Society \& Natural Resources, 10(3), 283-295, 1997. doi: 10.1080/08941929709381027

Sabourin, E.; Patrouilleau, M. M.; Francois, J.; Vásquez, L.; Niederle, P. (Orgs.). Políticas públicas a favor de la agroecología en América Latina y El Caribe. Red PPAL. Brasilia: FAO, 2017. 
Sauer, S.; Mészáros, G. The political economy of land struggle in Brazil under workers' party governments. Journal of Agrarian Change, 17(2), 397-414, 2017. doi:10.1111/joac.12206

Schmitt, C.; Niederle, P.; Ávila, M.; Sabourin, E.; Petersen, P.; Silveira, L.; Assis, W.; Palm, J.; Fernandes, G. B. G. La experiencia brasileña de construcción de políticas públicas en favor de la Agroecología. En: Sabourin, E. P. et al. (Orgs.). Políticas públicas a favor de la agroecología en América Latina y El Caribe. Brasilia: FAO, Red PP-AL, p. 44-69, 2017.

Scoones, I.; Edelman, M.; Borras, S. M. Jr.; Hall, R.; Wolford, W.; White, B. Emancipatory rural politics: Confronting authoritarian populism. The Journal of Peasant Studies, 45(1), 1-20, 2018. doi: 10.1080/03066150.2017.1339693

Sharp, G. From dictatorship to democracy. Boston: Albert Einstein Institute, 1994.

Spinoza, B. Ethics. Hertford, UK: Wordsworth Editions, 2001.

Stédile, J. P. Necesitamos una nueva estrategia de disputa del poder político. ALAI América en Movimiento, 2017. Disponible en: <https://www.alainet.org/es/ articulo/188764>. Acceso en: oct., 2018.

Steger, M. B. The quest for evolutionary socialism: Eduard Bernstein and social democracy. Cambridge: Cambridge University Press, 2006.

Timmermann, C.; Félix, G. Agroecology as a vehicle for contributive justice. Agriculture and Human Values, 32(3), 523-538, 2015. doi: 10.1007/s10460-014-9581-8

Vandermeer, J.; Aga, A.; Allgeier, J.; Badgley, C.; Baucom, R.; Blesh, J.; Shapiro, A.; Jones, L.; Hoey, M.; Jain, et al. Feeding prometheus: An interdisciplinary approach for solving the global food crisis. Frontiers in Sustainable Food Systems, 2, 39, 2018. doi: 10.3389/fsufs.2018.00039

Vázquez, L. L.; Marzin, J.; González, N. 2017. Políticas públicas y transición hacia la agricultura sostenible sobre bases agroecológicas en Cuba. En: Sabourin, E. P. et al. (Orgs.). Políticas públicas a favor de la agroecología en América Latina y El Caribe. Brasilia: FAO, Red PP-AL, p. 108-131, 2017.

Veltmeyer, H. Resistance, class struggle and social movements in Latin America: Contemporary dynamics. The Journal of Peasant Studies, 46(6), 1264-1285, 2019. doi: 10.1080/ 03066150.2018.1493458

Vergara-Camus, L.; Kay, C. Agribusiness, peasants, leftwing governments, and the state in Latin America: An overview and theoretical reflections. Journal of Agrarian Change, 17(2), 239-257, 2017. doi: 10.1111/joac.12215

Waddell, B. Laying the groundwork for insurrection: a closer look at the U.S. role in Nicaragua's social unrest. Global Americans, 2018. Disponible en: <https:// theglobalamericans.org/2018/05/laying-groundworkinsurrection-closer-look -u-s-role-nicaraguas-socialunrest/>. Acceso en: oct., 2018.

Webber, J. R. Evo Morales, transformismo, and the consolidation of agrarian capitalism in Bolivia. Journal of Agrarian Change, 17(2), 330-347, 2017. doi: 10.1111/ joac. 12209

Wezel, A.; Bellon, S.; Doré, T.; Francis, C.; Vallod, D.; David, C. Agroecology as a science, a movement and a practice. A review. Agronomy for Sustainable Development, 29(4), 503-515, 2009. doi: 10.1051/agro/2009004

Wilpert, G. Changing Venezuela by taking power: the history and policies of the Chavez government. London: Verso, 2007.

Wright, J. ¡Falta Petroleo! Perspectives on the emergence of a more ecological farming and food system in postcrisis Cuba. Wageningen-Holanda, Tesis, Universidad de Wageningen, 2005.

WWF - World Wide Fund for Nature. The growth of soy: impacts and solutions. Surrey, UK: Gland, 2014. 